This work has been submitted to NECTAR, the Northampton Electron ic Collection of Theses and Research.

\title{
Article
}

Title: Modes of communication during jazz improvisation

Creators: Seddon, F. A.

DOI: $10.1017 / S 0265051704005984$

Example citation: Seddon, F. A. (2005) Modes of communication during jazz improvisation. British Journal of Music Education. 22(1), pp. 47-61. 0265-0517.

Version: Published version

Official URL: http://dx.doi.org/10.1017/S0265051704005984

Note: Copyright 2005 Cambridge University Press

http://ne ctar.northampton.ac.uk/3663/

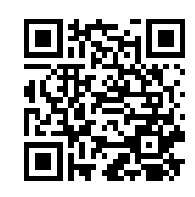




\section{Modes of communication during jazz improvisation}

\section{Frederick A. Seddon}

Department of Computing, Faculty of Maths and Computer Science, The Open University, Walton Hall, Milton Keynes, MK 7 6AA

f.a.seddon@open.ac.uk

This study investigated modes of communication adopted by six student jazz musicians during rehearsal and performance. Six one-hour rehearsal sessions and a performance were observed and videotaped for analysis. Results revealed six modes of communication that formed two main categories, verbal and non-verbal, each containing three distinct modes of communication: instruction, cooperation and collaboration. Non-verbal collaborative mode displayed empathetic attunement, which is a vehicle for empathetic creativity. Empathetic creativity is a theoretical concept proposed by the author based on the concept of empathetic intelligence (Arnold, 2003, 2004). Practical applications of empathetic creativity are discussed with reference to music education, focusing on evaluation of individual contribution to group creative performances.

\section{Introduction}

When jazz musicians play together they have at their disposal verbal communication, non-verbal communication (e.g. eye contact, aural cues and body language) and musical communication. These modes of communication operate during rehearsal and performance and can be influenced by the group's shared social and musical experiences. This study reveals modes of communication employed by six student jazz musicians. It investigates whether or not they are able to empathetically attune when improvising together.

\section{Musical communication in jazz}

Musical communication in jazz has been investigated using an ethnomusicological approach by Berliner (1994, 1997) and Monson (1996). These studies gathered musicians' views on how the practices of jazz and improvisation relate to their social worlds. Sawyer (1992) took a constructionist approach and conducted a series of interviews with professional jazz musicians in order to reveal the interactive nature of jazz improvisation. Conscious and non-conscious processes were found to operate simultaneously, producing a tension between individual performance and awareness of the other musicians. These studies focused on interviewing professional American jazz musicians and do not reveal either an English perspective or the experience of student jazz musicians. Some studies adopt a cognitive modelling of perceptual or generative processes (Sloboda, 1985; Pressing, 1988; Kenny \& Gellrich, 2002). Few studies have attempted to explain the psychological processes involved in jazz musicians' collaborative communication (although see Sawyer, 2003). This article argues that musical communication during improvisation aspires to 
'empathetic creativity', a concept proposed by the author based on the concept of 'empathetic intelligence' developed by Roslyn Arnold (Arnold, 1998, 2003, 2004).

\section{Background}

Arnold's theoretical concept of empathetic intelligence is based on liberal, democratic, student-centred educational philosophy influenced by John Dewey (1916, 1963, 1964, 1971). This philosophy influenced the student-centred, holistic pedagogy of the 1960s and '70s, when it became accepted that students could learn through exploration and direct experience. This approach to learning represents a shift in focus from matching the content and the method of pedagogy to required outcomes, to regarding pedagogy as a phenomenon of inter-subjective engagement. Arnold argues her case for empathetic intelligence from this pedagogical perspective. Her approach resonates with descriptions of how jazz musicians acquire and develop their improvisation skills: by combining personal performance histories with jazz's artistic traditions in order to absorb and exchange ideas (Berliner, 1994).

Arnold argues that inter-subjective engagement can be accessed through empathetic attunement during communication between educator and student (for a more detailed account see Seddon, 2004). Empathy is achieved by understanding the thoughts and feelings of self and others through attunement, decentring and introspection. Attunement prepares individuals for exploration, risk-taking, concentration and rapport and requires the development of trust between individuals. In this context attunement goes beyond focusing on self-absorption in aesthetically pleasing situations to include decentring in order to make an aesthetic judgement. Decentring serves to distinguish between sympathy and empathy: sympathy suggests we share common experiences but empathy encourages us to see things from another's point of view, experiencing layers of thought and feeling beyond what might be otherwise accessible. Introspection requires the capacity to reflect on past experience to guide future action by working through stored memories to select significant ones. The process of inter-subjective engagement accessed through empathetic attunement rooted in decentring and introspection during communication between educator and student can also occur when jazz musicians improvise together (Seddon, 2004).

\section{Empathetic creativity}

During improvisation jazz musicians deal with the internal constraints of the knowledge base acquired through deliberate practice (e.g. musical materials, excerpts and problemsolving routines). But they also deal with the external constraints of cultural referents (e.g. in jazz the 32-bar cycle of jazz standards, chords, and characteristic rhythmical patterns). Jazz musicians aspire to transcend their knowledge base in order to produce spontaneously created material rather than mere improvised fillers. This process involves risk-taking in a state of uncertainty where repetition and predictable responses become virtually impossible (Kenny \& Gellrich, 2002). When a group is improvising together the unpredictability of each individual's contribution implies that the performance is collaborative. Performers listen and respond to each other in a collaborative and inter-subjective performance (Sawyer, 1999). 
Musicians also have to be able to trust in, care about and respect the musical abilities of the other band members during performance, especially if they are taking musical risks. Musicians rely on each other to orient and reorient themselves, particularly when playing against the time (Monson, 1996). Improvisers can only avoid predictable responses by risktaking and self-challenge during group improvisation where they constantly reassess their responses in relation to the creative contributions of other individuals in the group (Kenny \& Gellrich, 2002). The relinquishing of authoritarian control in favour of a more democratic engagement in order to produce more creative results can be exemplified in Miles Davis's creation of ritualised performance space. Davis refused to provide authoritarian certainty in his group, creating a heightened form of group cohesion with democratic and dynamic exchanges. This meant that his musicians needed to listen and defer to one another's projections more closely than before (Kenny \& Gellrich, 2002). By listening and responding to other musicians a collaborative performance is produced. No one acts as a leader directing the performance; instead, the performance emerges out of the actions of everyone working together (Sawyer, 1999).

The role of emotion in music can be viewed as discursive, with emotion regarded as a form of social action rather than an internal state. Music is a powerful constructor of emotion in interactive contexts that can produce a 'community of sentiment' binding performers into something larger than the individual (Appadurai, 1993). Musical conversations are not conducted in a solely abstract, semiotic sense: they are created through interactions that are more than just linguistic properties. Inter-musical associations are not merely in the head but also in the heart and the body (Monson, 1996). Descriptions given by jazz musicians of sensations when 'striking a groove' include references to a great sense of relaxation increasing their powers of expression and imagination, being able to handle their instruments with athletic finesse and being able to respond to every impulse. They talk of states of mind where ideas are not blocked and of musical freedom. Individual musical thinkers show extraordinary receptiveness to each other, combining their talents to raise periods of communal creativity to a supreme level (Berliner, 1994, 1997).

Empathetically creative musicians are sensitive to 'attunement' in order to signal attention and 'mirroring' to affirm and modulate musical responses. Empathetic attunement requires more than individual aesthetic self-absorption in improvisation: it requires communication and collaborative aesthetic judgement. This form of empathetic attunement is exemplified by professional jazz musicians talking about their collaborative performances, as in the following extract:

'Another thing about bass players that's very important is their ability to concentrate when I or another member of the ensemble moves away from the basic pulse beat - and start playing against the time, if you will. It's not always the best idea...- when somebody else starts playing against the time - to hear that and go with them, because somebody has to stay grounded... When a bass player has the ability to concentrate and...the wisdom to know when to... play against the time and leave me as the centrepoint, that's very important and it's not anything that I would want to have to teach anyone... It's something that has to be there...the ability to absorb large amounts of variants without being thrown.' (Peterson, 1989, quoted in Monson, 1996: 174-5)

Musical attunement can occur at both a sympathetic and an empathetic level. At a sympathetic level of attunement there might be musical cohesion but clashes of musical 
styles, with interpretation of rhythms or accommodation of a weaker player preventing musicians from reaching the empathetic level. Empathetic attunement occurs when musicians are able to decentre and see things from other musical perspectives. During decentring improvisers are not only concerned with their collective time-keeping role, they also strive to achieve a collective transparency of sound where each part is discernible. They seek complementary rhythmic activity of an appropriate density within the space made available to them by the other musicians, and improvise melodies that will not obscure the performances of the others. Jazz musicians often refer to this as 'striking a groove' together (Berliner, 1994, 1997; Monson, 1996; Kenny \& Gellrich, 2002).

During improvisation sections a distinction may be drawn between the interplay of 'stocks of musical knowledge' and truly 'spontaneous musical utterances' (Davidson \& Good, 2002). For example, musicians describe how they listen to recordings they have made and hear themselves playing phrases they have never previously practised but which have emerged as a result of what the other musicians were playing at the time. These spontaneous musical utterances rely upon empathetic attunement between the musicians, which although rooted in the sharing of stocks of musical knowledge evolves beyond this process. Empathetic attunement, or 'striking a groove' (Berliner, 1994, 1997), is a heightened state of empathy when improvisers go beyond responding supportively to their fellow musicians and stimulate the conception of new ideas. It is proposed that empathetic attunement is a necessary prerequisite for the emergence of spontaneous musical utterances which exemplify empathetic creativity.

Investigating communication processes employed by musicians when they are improvising is a complex activity. Controlled experimental conditions with post-event analysis would influence the creative impetus for improvisation, which often depends on volatile performance variables (Kenny \& Gellrich, 2002). Improvisation is essentially a social process and should be investigated in a naturalistic environment (Monson, 1996). However, it is difficult to reveal what improvisers are thinking about at the precise moment of creation because at that time they do not have access to their own subconscious processes (Sloboda, 1985). The current study attempted to address these problems by employing a quasi-naturalistic design and a combination of videotaped observation techniques with verification of researcher interpretation through 'member checks' - a process of asking participants to tell you whether you have accurately described their experience (Lincoln \& Guba, 1985).

\section{Research context and methods}

The jazz course at the university where the current study was conducted incorporates three major aspects of learning to become a jazz musician. The first year is spent developing individual instrumental and improvisation skills. The second year extends students' shared socio-cultural knowledge through learning the standard jazz repertoire and performing together in impromptu and fluid bands. This is designed to train the students for the professional world of jazz where bands are often put together to perform at a gig with a minimum of prior rehearsal. The third year is spent developing shared personal and musical skills in more static ensembles. 
The aim of the research was to reveal the modes of communication employed by the student jazz musicians while rehearsing and performing.

The participants were 6 students ( 5 male, 1 female) pursuing an undergraduate Jazz course at a university situated in the south of England. All the students were adults in their second year of study and were used to playing together occasionally as part of their course evaluation.

The participants were asked to select a repertoire and rehearse together with the ultimate aim of performing at a 'gig' for one evening in their students' union bar. This meant that the task they were given differed slightly from their normal activities but was still closely related to their everyday activities (quasi-naturalistic). In order to investigate student modes of communication the study was designed as an exploratory observation study. In order to reveal their modes of communication the students agreed to be observed and videotaped during six one-hour group rehearsals and the 40-minute performance gig.

The analysis of the videotapes was adapted from a procedure used for the qualitative analysis of text, first used by the researcher in a previous study investigating composition strategies (Seddon \& O'Neill, 2003). This method of analysis is based upon 'grounded theory' (Glaser \& Strauss, 1967), where categories emerge through a process of inductive reasoning rather than the data being allocated to predetermined categories. The adaptation was based on the constant comparative method (Glaser \& Strauss, 1967; Lincoln \& Guba, 1985), which involves five main stages: immersion, categorisation, phenomenological reduction, triangulation and interpretation (McLeod, 1994), as follows:

- Stage 1: Immersion. A detailed transcript was made of the videotaped data, aiming to capture the rich descriptive nature of the process observed.

- Stage 2: Categorisation. Systematically working through the data assigning communication categories to the observed participant interaction, leading to the emergence of evidence of different types of communication.

- Stage 3: Phenomenological reduction. Similar types of communication were grouped together, revealing 'themes'. When a type of communication emerged that could not be included in an existing group, a new group was formed to accommodate it, leaving room for a continuous refinement in the grouping. Six different types of communication were revealed through this process: verbal and non-verbal types of communication, each related to the activities of instruction, cooperation and collaboration.

- Stage 4: Triangulation. Videotaped examples of the six types of communication were presented to participants along with researcher interpretations of each type of communication. In a process known as 'Member checks', the participants were then asked to comment on the researcher's interpretations.

- $\quad$ Stage 5: Interpretation. This stage involved making sense of the data from a wider perspective, constructing a model or using an established theory to explain the findings of the study.

Hoogsteder, Maier and Elbers (1998), in a study investigating interaction during joint problem-solving, describe a 'mode' of interaction as a communicative framework that gives meaning to the participants' activities.

As each of the six types of communication displayed by the participants in the current study was linked to a particular activity (instruction, cooperation and collaboration), 
the different types of communication were interpreted as 'modes' of communication. These modes of communication were verbal/non-verbal instruction, verbal/non-verbal cooperation, and verbal/non-verbal collaboration.

Verbal instruction emerged mainly when the group was beginning rehearsal of a piece and provided an appropriate non-democratic mode of communication for initiating performance. Verbal cooperation emerged each time musical communication either broke down or was suspended. It provided a medium for the musicians to clarify, evaluate and adapt organisational issues, which did not involve creative issues. Verbal collaboration also emerged when musical communication was suspended or broke down. It involved the expression of more group creative preferences, which gave a sense of the creative development of the piece belonging to the group rather than the individual.

Non-verbal instruction served the same role as verbal instruction in that it was used to initiate a piece and as a means to communicate the pre-composed sections of the piece between the musicians (e.g. learning by ear or reading the score). Non-verbal cooperation was employed when the group was engaged in playing together and included musical and visual cues. These communications were restricted to promoting cohesion, and when they proved unsuccessful (in rehearsal), playing would often cease and be replaced by verbal communication. Non-verbal communication, both musical and visual, required sympathetic attunement between the musicians to be successful even though it addresses cohesive rather than creative issues. Non-verbal collaboration took place when the musicians were playing together in an empathetically attuned condition. This facilitated creative musical development during the improvised solos and produced a perceptible 'atmosphere' between the musicians.

Two of the modes of communication, cooperative verbal and non-verbal, were revealed to be related to activities facilitating cohesive performance of the music. Two of the modes of communication, collaborative verbal and non-verbal, were revealed to be related to activities facilitating creative developments in the content of the music. The modes of communication related to cohesive performance were interpreted as being of a lower order than those related to creative development in the content of the music. Underwood and Underwood (1999) support this hierarchical distinction between 'cooperative' and 'collaborative' modes: cooperative modes are associated with lower level cohesive processes and collaborative modes are associated with higher level creative processes (Underwood \& Underwood, 1999). A further hierarchical distinction was made between sympathetic and empathetic levels of attunement between the participants (Arnold, 1998, 2003, 2004; Seddon, in press). Evaluation of the improvisations produced was based upon researcher judgements of the production of 'spontaneous musical utterances' as distinct from the 'exchange of stocks of musical knowledge' (Davidson \& Good, 2002), along with support from participant judgements of the same improvisations.

\section{Results}

Six modes of communication formed two main categories, verbal and non-verbal, each containing three distinct modes of communication: instruction, cooperation and collaboration (see Table 1). 
Table 1 Modes of communication

\begin{tabular}{|c|c|c|}
\hline Mode of communication & Verbal & Non-verbal \\
\hline Instruction & $\begin{array}{l}\text { Musicians are told what } \\
\text { and when to play in } \\
\text { pre-composed sections } \\
\text { (the head) }\end{array}$ & $\begin{array}{l}\text { Musicians learn } \\
\text { pre-composed part by ear } \\
\text { or read from music } \\
\text { notation }\end{array}$ \\
\hline Cooperation & $\begin{array}{l}\text { Musicians discuss and plan } \\
\text { the organisation of the } \\
\text { piece prior to } \\
\text { performance in order to } \\
\text { achieve a cohesive } \\
\text { performance }\end{array}$ & $\begin{array}{l}\text { Musicians achieve } \\
\text { sympathetic attunement } \\
\text { and exchange stocks of } \\
\text { musical knowledge, } \\
\text { producing cohesive } \\
\text { performance employing: } \\
\text { body language, facial } \\
\text { expression, eye contact, } \\
\text { musical cues and } \\
\text { gesticulation }\end{array}$ \\
\hline Collaboration & $\begin{array}{l}\text { Musicians discuss and } \\
\text { evaluate their } \\
\text { performance of the music } \\
\text { in order to develop the } \\
\text { content and/or style of } \\
\text { the piece }\end{array}$ & $\begin{array}{l}\text { Musicians achieve } \\
\text { empathetic attunement, } \\
\text { take creative risks which } \\
\text { can result in spontaneous } \\
\text { musical utterances. } \\
\text { When they do, this } \\
\text { signals empathetic } \\
\text { creativity }\end{array}$ \\
\hline
\end{tabular}

Verbal modes

A verbal communication was interpreted as instruction when a member of the group gave specific verbal instructions on how a pre-composed section of the piece should be performed without requiring any discussion. For example, during a rehearsal Laura gives the rest of the band clear instructions on the structure of her piece:

Laura: 'Right, it's Pete and Chris playing what they just played ...'

Keith: 'Twice or ...?'

Laura: 'Just once.'

A verbal communication was interpreted as cooperation when discussion between the musicians regarding possible organisational changes (e.g. the form, sequence of solos and possible endings) took place in a democratic way. These organisational changes to the form of the piece allowed the musicians to achieve a cohesive performance by agreeing the basic form of the piece beforehand. For example, during rehearsal, after playing a piece through, the following group discussion evaluating the organisation of the piece took place:

Chris: 'It worked.'

Pete: 'It wasn't too bad, was it?' 
Anthony: 'So what does it do...you know, when it gets into the solos?'

Pete: 'Yeah ... in between each solo you nod when you get to the last one.'

Anthony: 'Yeah, yeah, yeah, but I mean, it goes erm ...der...der der...der, der, der

[sings phrase] ... and you're straight in there, aren't you?'

Pete: 'That's on the top - that der... der...der ... is at the top of the solo, yeah.'

A verbal communication was interpreted as collaborative when discussion regarding possible creative changes took place in a democratic way. During verbal collaboration creative changes were discussed, developed and implemented following group evaluation of both the piece and the musicians' individual and combined performances. For example, during rehearsal, after playing a piece through, the following group discussion evaluating the 'feel' of the piece took place:

Paul: 'I didn't think the feel worked for me in the solo ... it doesn't really happen ...'

Chris: 'The blow [improvised solo playing] over it?'

Paul: 'Well, just the whole feel of it ... the whole ...'

Laura: 'I think maybe we could try it a bit quicker.'

Chris: 'Yeah.'

Anthony: 'Yeah.'

Paul: 'You didn't want to swing it ... did you or did you?'

Keith: 'I don't think you would be able to swing it anyway. It would sound like a completely different tune ...'

\section{Non-verbal modes}

A non-verbal communication was interpreted as instruction when there was a musical dialogue consisting mainly of one musician demonstrating how a pre-composed section of the piece should sound by playing it on an instrument or vocalising the tune. For example, during a rehearsal the group wanted to learn a new piece but they had no written copy of it, so one of the musicians who knew the piece played it for the others to learn by ear.

A non-verbal communication was interpreted as cooperation when the musicians became sympathetically attuned, displaying non-verbal communication (e.g. body language, facial expression, eye contact, musical cues and gesticulations). This mode of communication facilitated a cohesive performance and at times contained sympathetically attuned musical cues that focused on cohesive issues rather than creative issues.

A non-verbal communication was interpreted as collaboration when communication was conveyed exclusively through musical interaction and focused on creative exchanges. This non-verbal creative musical communication requires empathetic attunement to occur and provides the potential vehicle for empathetic creativity to emerge through spontaneous musical utterances.

Researcher judgements of sympathetic vs. empathetic attunement were made based upon comparisons of observed participant communication, both visual and musical, produced during videotaped observation sessions. When sympathetically attuned, the musicians were perceived to be drawing on their musical knowledge base and improvising without taking risks or challenging their individual or collective creativity. Sympathetic attunement was visually evident in expressions of relative disinterest (e.g. no smiles, 
affirmative nods or energetic body movements). Sympathetic attunement was musically evident in comparatively predictable, complementary musical responses, providing musical cohesion without creative risk through sharing stocks of musical knowledge. When empathetically attuned, the musicians seemed to respond to each other in an atmosphere of risk-taking and challenge which extended their knowledge base. They took risks with musical phrases and timing and in so doing challenged each other's musical creativity. Empathetic attunement was visually evident in expressions of interest (e.g. smiles, collective affirmative nodding and animated body movements). Empathetic attunement was musically evident in the production of unpredictable musical 'invitation' or 'response' when participants engaged each other in challenging musical interaction. Researcher interpretation indicated that responses went beyond cohesive modes of communication to creative modes of communication.

\section{Member checks}

To provide validation of researcher interpretations of the modes of communication, participants were shown video clip examples of each of the modes of communication and asked to review and critique the research of which they were the focus. This procedure is known as 'member checks', where participants are asked to tell researchers if they have accurately described their experience and produced a 'recognisable reality' (Lincoln \& Guba, 1985; Brown \& Gilligan, 1992). Examples of participant responses to researcher interpretations were:

Verbal instruction:

'I agree that this [verbal instruction] is what this clip illustrates. I was clearly instructing the group as to the form of the piece and what I wanted them to do.'

Verbal cooperation:

'I agree, when the composer brings a piece to rehearse, he/she may call upon the experience and judgement of the other musicians to improve the structure... This may include the order or length of certain sections, the instrumentation... and any other aspect of the prescribed organisation.'

Verbal collaboration:

'I was glad they could tell me the things that didn't really work or they weren't happy with, sort of work in progress. This made the piece more alive. I found it a bit hard to really assert what I wanted because I also wanted us to make it our piece, not just my piece.'

Non-verbal instruction:

I agree with this definition [referring to researcher interpretation of non-verbal instruction]. The pre-composed part could also be backings behind a solo, which could be taught aurally off the cuff. In a funk or groove setting I think this happens far more.'

Non-verbal cooperation:

II strongly agree with this [description of and video example of non-verbal cooperation]. It is part of the language of being a jazz musician. Certain gestures 
and facial expressions denote certain things within a jazz setting, for example patting your head indicating play the head, or to go back to the top.'

Non-verbal collaboration:

I would liken empathetic attunement to a conversation which is flowing very smoothly where everybody is acutely listening to each other and everybody feels comfortable enough to speak freely whenever they wish. I agree that empathetic attunement can result when exploration and risk-taking has been set up within the piece previously, although not always necessarily. Sometimes just sitting on something repetitively can bring this empathetic interplay...I agree that spontaneous musical utterances can result from this, when you surprise yourself with an idea. For myself, these utterances come from a feeling of being safe, relaxed and accepted by the musicians I'm playing with, and a non-judgemental atmosphere within the group. I think 'licks' [musical motifs] are a part of jazz language, and spontaneously creating your own licks is a very good feeling.'

It should be noted that there is a potential for researcher bias to influence member checks. For example, when the researcher describes the interpretations made, the participant may be influenced by the researcher and/or may find it difficult to disagree with the researcher's interpretation. During the member checks procedure in the current study the researcher was aware of the potential for bias and made every effort to describe the interpretations objectively and allow the participants every opportunity to disagree. Moreover, a good rapport was developed between the participants and the researcher over several months, which allowed for occasional disagreements over interpretations to emerge. It should also be noted that the participants were adults with very strong professional opinions about what they were doing and were used to voicing such opinions.

To provide further validation of researcher interpretations of sympathetic and empathetic attunement, participants were also shown video clip examples from the performance gig of two solos identified by the researcher and one participant (Chris, tenor sax) as being examples of the band being 'empathetically attuned' and 'not being empathetically attuned'. After having viewed the video clips as often as they requested, participants were asked to comment on them in relation to how they felt about them being described as being examples of the band being 'empathetically attuned' and 'not being empathetically attuned'. There was some agreement with the researcher's interpretations but this was not unanimous.

Comments on the 'empathetic attunement' video clip were as follows:

'I was enjoying what Chris was playing, he seemed to really like this piece. Overall I think we had a good energy here as a band I think, although not sure we were totally attuned at this point. It wasn't really flowing I don't think.' (Laura, keyboard)

'In the clip "empathetic attunement" from the live gig, it is certainly true that something special seems to happen. Chris rises through several nice phrases before reaching a long and held note at the peak before descending through the horn and backing off the microphone. It is interesting that Chris felt this was a particularly creative moment, and I feel that it happened more or less by chance. From my experience it is possible to come away from a playing situation when one musician might feel that it was "happening", or "in the groove", and others may feel it was not for them. It's a very 
subjective thing, and I think it can be related to how one felt about one's own playing. One could hear a group, approach one of the members and say the music sounded great, only to find that it "wasn't happening" for them. I think this can be related to people's personal perception at that time and can be influenced by all sorts of things such as mood, confidence and experience. I think the goal must be for everyone to feel the creative empathetic state before spontaneous musical utterances occur, which are to a large extent objective in nature as they can be identified.' (Paul, bass)

Comments on the 'Not empathetic attunement' video clip were as follows:

'I thought the rhythm section were interacting better here than in Chris's solo ['empathetically attuned' example] actually, despite Pete getting lost in the form. It was a bit painful I was trying to really make the chords clear in the hope Pete would be able to hear where he was. I was trying to mark the top, with my hand, but could have made it clearer for him. I think the rhythm section (Keith, Paul and me) were listening quite well to each other at this point, it actually heightened our ears because it was potentially a car crash and we wanted to avoid that!' (Laura, keyboard)

The researcher perceived no spontaneous musical utterances here and this was confirmed by all the participants during member checks, therefore there were no actual examples of empathetic creativity.

\section{Discussion}

Researcher identification and interpretation of the six modes of communication were supported by participant member checks. These six modes of communication provide support for the theoretical concept of empathetic creativity being the production of spontaneous musical utterances that can emerge from empathetically attuned collaborative musical communication. There was agreement between the researcher and some participants about the occurrence of periods of empathetic attunement during both rehearsal and performance. The researcher and all participants were in agreement that no spontaneous musical utterances were produced during the period of the study. The researcher observed a link between the activity engaged in and the mode of communication adopted. Instructional modes were adopted during initiation of the rehearsal of a piece. Cooperational modes were adopted when developing the cohesive nature of a piece. Collaborative modes were adopted for developing creative aspects of the piece. This supported the findings of Hoogsteder, Maier and Elbers (1998), who report that modes of interaction had a typical dynamic that was linked to the overall activity of their participants.

The theoretical concept of empathetic creativity is proposed in an attempt to clarify, explain and provide an objective vocabulary to describe specific psychological processes involved in the phenomenon 'empathetic attunement', often referred to in the literature as 'striking a groove' (Berliner, 1994, 1997). Much of the literature addressing this phenomenon is grounded in retrospective enquiry, with experienced jazz musicians providing rich, recollected descriptions of psychological and physical states when 'striking a groove'. These descriptions indicate a collaborative creative communication occurring while the musicians are in a collective 'altered state of mind', which results in extraordinary technical functioning, enhanced creative communication and creative 
product. Professional jazz musicians acquire the ability to reach this pinnacle of peak improvised performance by gaining mastery of their instrument, immersing themselves in the jazz community's traditional education system and by developing longer-term, collaborative musical and social relationships (Berliner, 1994, 1997; Monson, 1996; Kenny \& Gellrich, 2002). It is proposed that during this process they learn to become collectively attuned when performing and improvising. At one level this attunement is sympathetic, allowing for a cohesive performance revolving around sharing stocks of musical knowledge. At another level this attunement becomes empathetic, which is differentiated from sympathetic by collaborating musicians either consciously or subconsciously engaging in the psychological processes of decentring and introspection in order to become empathetically attuned. Once empathetically attuned, an atmosphere of trust allows for creative risk-taking, which can result in the production of spontaneous musical utterances that may be regarded as examples of empathetic creativity.

\section{Implications for music education}

By studying jazz students as they are inducted into the profession it is possible to take a 'snapshot in time' to reveal whether or not they have developed the ability to achieve empathetic attunement, making empathetic creativity possible. The current study indicates that for the student jazz musicians performing in their educational environment during the data collection period empathetic attunement was achievable for sub-groups of the band but was never achieved by all members of the band simultaneously. There are several possible explanations for this lack of simultaneous empathetic attunement. Because the study focused on students in the second year of their studies, the participants may not yet be experienced enough to become regularly empathetically attuned. This lack of experience may have inhibited decentring, introspection and the development of trust, all of which are necessary precursors to empathetic attunement. The social environment could have influenced the group collaborative communication. The students are usually continuously assessed during group performance, which can add pressure during performance. This pressure could undermine congeniality and inhibit feelings of safety and security, which would not be conducive to collective risk-taking.

There was an example of one member of the band experiencing what he believed was empathetic attunement that was not experienced by his fellow band members. In this case the individual could have been experiencing an individual optimal or 'flow' experience (Csikszentmihalyi \& Csikszentmihalyi, 1988). This might indicate that he was engaged in individual aesthetic self-absorption in improvisation (sometimes colloquially referred to as being self-indulgent). Decentring requires communication and collaborative aesthetic judgement that could have been lacking in this individual because he was relatively inexperienced as a jazz musician. Further research is required to investigate this important question. Empathetic attunement is an optimal condition in collaborative creative music-making or a collaborative 'flow' experience (Csikszentmihalyi \& Rich, 1997; O’Neill, 1999).

This study was initiated as a result of the researcher attending a course on the evaluation of the individual within group creative activities held at the university where the current study was conducted. After attending the course the researcher believed that the process of 
evaluation employed at the university was largely based upon a number of intuitive, nonexplicit and non-transparent expert responses to individual student contribution within a group performance. These evaluations were based on the experts' considerable and highly professional experience conducted within a 'classical conservatoire model' (Kingsbury, 2001). Although there are many positive aspects to this kind of expert consensual assessment evaluation (see Amabile, 1996; Hickey, 2001; Webster \& Hickey, 1995), the lack of explicitness and transparency is problematic in the current evaluative education environment. This kind of evaluation also fails to take into account the student's perspective, which can be crucial to learning (Seddon \& O'Neill, 2004).

It is hoped that the results of the current study could help to develop an evaluation process that would make explicit and transparent aspects of individual contribution to creative collaborative performance. The results of this study identify the concepts of verbal/non-verbal instruction, cooperation and collaboration, sympathetic and empathetic attunement, and the associated psychological attributes of decentring and introspection. These concepts and psychological attributes can be identified and evaluated by educators in a process that could include student self-evaluation and validation. The study also provides a specific vocabulary that can facilitate discussion between expert evaluators and students, which could improve the evaluation process. This new potential evaluation process has been conducted in a jazz education context on this occasion but would be transferable to other music education contexts that evaluate individual contribution to group creative performances.

\section{Opportunities for future research}

The lack of agreement between participants themselves, and on occasion with the researcher, highlights a major problem in investigating this phenomenon. Future research should conduct videotape-stimulated Retrospective Verbal Protocol (RVP) (Richardson \& Whitaker, 1996) immediately after rehearsal and performance with individual musicians and as a group to enable comparisons between responses to be made. This would ensure any individual or sub-group attunement not experienced by the group as a whole would be revealed.

Using observation techniques to research the communication processes employed by improvising musicians is also methodologically problematic because it can be over-reliant on researcher interpretation of observed behaviour. The musicians may be employing subconscious cognitive and affective processes during improvisation that do not produce observable behaviours. Empathetic creativity emerges during empathetic attunement, which, like 'striking a groove', is an 'altered state of mind' that inhibits concurrent verbal protocols. Retrospective verbal protocols rely on memory, and individuals can be influenced by collective, often exaggerated, 'folklore'-influenced accounts of previous musical events. The current study attempted to address the methodological problems discussed above through the use of a combination of data collection and analysis techniques. Videotaperecorded observation allowed for researcher interpretations to be validated by participant perspectives provided by member checks; future studies could include further validation procedures undertaken by independent researchers. Future studies could also be improved by adopting a longitudinal design that could follow a group of jazz students from the 
beginning of their course through to the end and possibly beyond, into their professional careers. A longitudinal study might reveal the progressive acquisition of individual musical and psychological attributes (e.g. decentring and introspection) and their application to collective musical performance, giving further support to the proposed theoretical concept of empathetic creativity.

\section{Acknowledgements}

The author would like to thank the participants for generously giving their time at a particularly busy period in their studies. I am also grateful to Margaret Barratt for introducing me to Roslyn Arnold's work on empathetic intelligence, which enabled me to develop my theoretical concept of empathetic creativity.

\section{References}

AMABILE, T. M. (1996) Creativity in Context. Oxford: Westview Press.

APPADURAI, A. (1993) 'Topographies of the self: praise and emotion in Hindu India', in C. A. Lutz \& L. AbuLughod (Eds.), Language and the Politics of Emotion, 92-112. Cambridge/Paris: Cambridge University Press/Editions de la Maison des Sciences de L'Homme.

ARNOLD, R. (1998) 'The role of empathy in teaching and learning'. The Education Network, 14 (December).

ARNOLD, R. (2003) 'Empathetic intelligence: the phenomenon of intersubjective engagement'. Paper presented at the First International Conference on Pedagogies and Learning, 1-4 October, University of Southern Queensland.

ARNOLD, R. (2004) Empathic Intelligence: Relating, Educating, Transforming. Sydney: University of New South Wales Press.

BERLINER, P. F. (1994) Thinking in Jazz: The Infinite Art of Improvisation. Chicago, IL: University of Chicago Press.

BERLINER, P. F. (1997) 'Give and take: the collective conversation of jazz performance', in R. K. Sawyer (Ed.), Creativity in Performance, 9-41. Greenwich, CT: Ablex.

BROWN, L. M. \& GILLIGAN, C. (1992) Meeting at the Crossroads: Women's Psychology and Girls' Development. Cambridge, MA: Harvard University Press.

CSIKSZENTMIHALYI, M. \& CSIKSZENTMIHALYI, I. (1988) Optimal Experience: Psychological Studies of Flow in Consciousness. Cambridge: Cambridge University Press.

CSIKSZENTMIHALYI, M. \& RICH, G. (1997) 'Musical improvisation: a systems approach', in R. K. Sawyer (Ed.), Creativity in Performance, 43-66. Greenwich, CT: Ablex.

DAVIDSON, J. W. \& GOOD, J. M. M. (2002) 'Social and musical co-ordination between members of a string quartet: an exploratory study'. Psychology of Music, 30, 2, 186-201.

DEWEY, J. (1916) Democracy and Education: An Introduction to the Philosophy of Education. New York: Macmillan.

DEWEY, J. (1963) Freedom and Culture. New York: Capricorn Books.

DEWEY, J. (1964) John Dewey: Selected Writings, ed. R. Archambault. New York: Modern Library.

DEWEY, J. (1971) The Child and the Curriculum and the School and Society. Chicago, IL: University of Chicago Press.

GLASER, B. G. \& STRAUSS, A. L. (1967) The Discovery of Grounded Theory. Chicago, IL: Aldine.

HICKEY, M. (2001) 'An application of Amabile's consensual assessment technique for rating the creativity of children's musical compositions'. Journal of Research in Music Education, 49, 3, $234-44$. 
HOOGSTEDER, M., MAIER, R. \& ELBERS, E. (1998) 'Adult-child interaction, joint problem solving and the structure of co-operation', in M. Woodhead, D. Faulkner \& K. Littleton (Eds.), Cultural Worlds of Early Childhood, 178-95. London: Routledge.

KENNY, B. J. \& GELLRICH, M. (2002) 'Improvisation', in R. Parncutt \& G. E. McPherson (Eds.), The Science \& Psychology of Music Performance: Creative Strategies for Teaching and Learning, 117-34. Oxford: Oxford University Press.

KINGSBURY, H. (2001) Music, Talent and Performance: A Conservatory Cultural System. Philadelphia, PA: Temple University Press.

LINCOLN, Y. \& GUBA, E. (1985) Naturalistic Enquiry. Beverly Hills, CA: Sage.

MCLEOD, J. (1994) Doing Counselling Research. London: Sage.

MONSON, I. (1996) Saying Something: Jazz Improvisation and Interaction. Chicago, IL: University of Chicago Press.

O'NEILL, S. A. (1999) 'Flow theory and the development of musical performance skills'. Bulletin of the Council for Research in Music Education, 141, 129-34.

PRESSING, J. (1998) 'Improvisation methods and models', in J. A. Sloboda (Ed.), Generative Processes in Music: The Psychology of Performance Improvisation and Composition, 129-78. Oxford: Clarendon Press.

RICHARDSON, C. \& WHITAKER, N. (1996) 'Thinking about Think Alouds in music education research'. Research Studies in Music Education, 6, 38-49.

SAWYER, R. K. (1992) 'Improvisational creativity: an analysis of jazz performance'. Creativity Research Journal, 5, 3, 253-63.

SAWYER, R. K. (1999) 'Improvised conversations: music collaboration and development'. Psychology of Music, 27, 2, 192-204.

SAWYER, R. K. (2003) Group Creativity: Music, Theatre, Collaboration. Mahwah, NJ: Lawrence Erlbaum Associates.

SEDDON, F. A. (2004) 'Empathetic creativity: the product of empathetic attunement', in D. Miell \& K. Littleton (Eds.), Collaborative Creativity, 65-78. London: Free Association Books.

SEDDON, F. A. \& O'NEILL, S. A. (2003) 'Creative thinking processes in adolescent computer-based composition: an analysis of strategies adopted and the influence of formal instrumental musical training'. Music Education Research, 5, 2, 125-38.

SEDDON, F. A. \& O'NEILL, S. A. (2004) 'The application of Q-methodology to the study of criteria used by adolescents in the evaluation of their musical compositions'. Musicae Scientiae, 8, 2, 207-29.

SLOBODA, J. A. (1985) The Musical Mind: The Cognitive Psychology of Music. Oxford: Clarendon Press.

UNDERWOOD, G. \& UNDERWOOD, J. (1999) 'Task effects on co-operative and collaborative learning with computers', in K. Littleton \& P. Light (Eds.), Learning with Computers: Analysing Productive Interaction, 10-23. London: Routledge.

WEBSTER, P. \& HICKEY, M. (1995) 'Rating scales and their use in assessing children's music compositions'. Quarterly Journal of Music Teaching and Learning, 6, 4, 28-44. 